\title{
Relationship Between the Length of Cell Cycles, Cleavage Pattern and Developmental Competence in Bovine Embryos Generated by In Vitro Fertilization or Parthenogenesis
}

\author{
Tamás SOMFAI ${ }^{1) \#}$, Yasushi INABA ${ }^{1) \#}$, Yoshio AIKAWA ${ }^{1)}$, Masaki OHTAKE ${ }^{1)}$, \\ Shuji KOBAYASHI ${ }^{1)}$, Kazuyuki KONISHI ${ }^{1)}$ and Kei IMAI ${ }^{1)}$ \\ 1) National Livestock Breeding Center, Fukushima 961-8511, Japan \\ \#Present: National Institute of Livestock and Grassland Science, Ibaraki 305-0901, Japan
}

\begin{abstract}
This study was conducted to study the kinetics of initial cell divisions in relation with the cleavage patterns in viable (with the ability to develop to the blastocyst stage) and non-viable bovine embryos and parthenotes. The kinetics of in vitro development and cleavage patterns were observed by time lapse cinematography. The length of the first and second but not third cell cycle differed significantly between the viable and non-viable embryos after IVF or parthenogenesis. Viable embryos had significantly shorter first and second cell cycles than non-viable ones. The presence of fragments, protrusions and unequally-sized blastomeres was associated with an extended one-cell stage and reduced ability to develop to the blastocyst stage; however, the lengths of the second and third cell cycles were not altered. Oocytes showing direct division from one cell to 3 or 4 blastomeres showed similar developmental ability and embryonic cell numbers to those showing normal division, although, with a high frequency of chromosomal abnormalities. Our results suggest that the differences in the first cell cycles between viable and non-viable embryos were not sperm-related, whereas direct cleavage of 1-cell embryos to 3 or more blastomeres and protrusion formation are related to sperm-driven factors. The length of the first and second cell cycles and the cleavage pattern should be examined simultaneously to predict developmental competence of embryos at early cleavage stages.
\end{abstract}

Key words: Bovine, Cleavage pattern, Developmental kinetics, Embryo, In vitro culture, Time lapse cinematography

(J. Reprod. Dev. 56: 200-207, 2010)

$\mathbf{R}$ ecent progress in the improvement of in vitro embryo production (IVP) systems allows us to produce large quantities of bovine embryos [1]. Nevertheless, the developmental competence of embryos produced by IVP is still inferior to that of in vivo produced embryos due to by different stresses resulting from the imperfection of the IVP systems in imitating in vivo conditions [2, 3]. Selection of embryos with good developmental competence is essential to achieve high success rates by transfer of embryos, especially when only one or a very few embryos are transferred into a surrogate mother at one time, such as in humans and cattle. The transfer of mammalian embryos at early cleavage stages (e.g., at the 1-8 cell stage) may have the advantage of avoiding stresses caused by the culture systems. Human embryos produced by assisted reproduction technology are still often selected and transferred at the cleavage stage [4]. Finding the most reliable marker of developmental competence in early embryos is still a matter of quest and debate among researchers. The number, morphology and position of pronuclei are often evaluated to estimate embryo quality in humans [5]; however, controversial data regarding these selection markers have also been reported [6, 7]. Moreover oocytes of large farm animals such as pigs and cattle contain a high number of lipid droplets that completely block the visibility of pronuclei using

Received: June 9, 2009

Accepted: November 6, 2009

Published online in J-STAGE: December 25, 2009

(C)2010 by the Society for Reproduction and Development

Correspondence: K Imai (e-mail: k0imai@nlbc.go.jp)

traditional microscopy. Therefore, these selection criteria are omitted in these species. The timing of the first cleavage is considered to be a rather reliable marker of embryo developmental competence in mice [8], humans [9-11], cattle [12-15] and pigs [16]. The reason for this phenomenon is not clearly understood since a number of paternal, maternal and other factors seem to be involved in the timing of first cleavage [17]; however, a previous study comparing IVP, parthenogenetic and nuclear transfer embryos has suggested the dominance of maternal factors [18]. In humans, evaluation of embryo quality based on morphological appearance at the first and second embryonic cleavages is also widely applied, as the formation of fragments [5, 19-22] or unevenly sized blastomeres [22, 23] seems to be associated with impaired developmental competence. These morphological criteria during early cleavage have been reported to correlate with the developmental ability of porcine embryos as well [16]. In humans, other cell division anomalies have also been observed, such as cleavage from one cell to three blastomeres and formation of protrusions and tripolar or tetrapolar spindles [24, 25]. Little is known, however, about the occurrence and consequences of these phenomena in IVP systems for farm animals. Although study of parthenotes may help us to understand the reasons for developmental anomalies by neglecting the paternal factors of embryogenesis, we have no information on such abnormal cleavage patterns of oocytes after parthenogenetic activation. These cleavage anomalies may remain undetected when the embryo developmental status is determined by occasional viewing. Recent developments in time-lapse cinematography systems, how- 
ever, enable measurement of the length of each developmental stage and observation of embryo morphology simultaneously. The present study was conducted to study the kinetics of initial cell divisions in relation with the cleavage patterns in viable and nonviable bovine embryos produced either by in vitro fertilization (IVF) or parthenogenesis and to assay their consequences on the cell and chromosome numbers in the resultant blastocysts.

\section{Materials and Methods}

\section{Oocyte collection and in vitro maturation (IVM)}

Collection and IVM of bovine follicular oocytes were performed as described previously [26]. Ovaries from approximately 28-32 month old Japanese Black heifers were collected at a local slaughterhouse, transported to the laboratory and then washed and stored in physiological saline supplemented with $50 \mu \mathrm{g} / \mathrm{ml}$ gentamicin (Sigma Chemical, St. Louis, MO, USA) at $20 \mathrm{C}$ for approximately $20 \mathrm{~h}$. Cumulus-oocyte complexes (COCs) were aspirated from small follicles (2-6 mm in diameter) using a 5-ml syringe with a 19-gauge needle and used for IVM. The maturation medium was 25 mM Hepes buffered TCM199 (M199, Gibco BRL, Grand Island, NY, USA) supplemented with 5\% calf serum (CS, Gibco BRL). COCs were washed twice with maturation medium and cultured for $20 \mathrm{~h}$ in 600 - $\mu$ l droplets (in groups of $80-100 /$ droplet) of maturation medium covered by paraffin oil (Paraffin Liquid; Nacalai Tesque, Kyoto, Japan) in 35-mm Petri dishes (Nunclon Multidishes, Nalge Nunc International, Roskilde, Denmark) at 38.5 $\mathrm{C}$ in $5 \% \mathrm{CO}_{2}$ in air with saturated humidity.

\section{IVF}

IVF was carried out as reported previously [26]. Briefly, at the end of IVM, ejaculated and frozen semen of a Japanese Black bull was thawed in a $37 \mathrm{C}$ water bath for $30 \mathrm{sec}$ and then centrifuged in $3 \mathrm{ml}$ of a $90 \%$ Percoll solution at $740 \times g$ for $10 \mathrm{~min}$. Then, the pellet was re-suspended and centrifuged at $540 \times g$ for $5 \mathrm{~min}$ in $6 \mathrm{ml}$ of sperm washing medium composed of Brackett and Oliphant solution (BO) [27] supplemented with $10 \mathrm{mM}$ hypotaurine (Sigma) and $4 \mathrm{U} / \mathrm{ml}$ heparin (Novo-Heparin Injection 1000, Aventis Pharma, Tokyo, Japan). The pellet was consequently re-suspended in sperm washing medium and BO solution supplemented with $20 \mathrm{mg} / \mathrm{ml}$ bovine serum albumin (BSA, crystallized and lyophilized, Sigma) to achieve the final concentrations of $3 \times 10^{6}$ spermatozoa $/ \mathrm{ml}, 5$ $\mathrm{mM}$ hypotaurine, $2 \mathrm{U} / \mathrm{ml}$ heparin and $10 \mathrm{mg} / \mathrm{ml}$ BSA. One hundred- $\mu$ l droplets of this suspension prepared in 35-mm plastic dishes and covered by paraffin oil served as fertilization droplets. The COCs were removed from the maturation medium, washed twice in BO supplemented with $10 \mathrm{mg} / \mathrm{ml} \mathrm{BSA}$, placed in fertilization droplets (20 COCs/droplet) and cultured for $6 \mathrm{~h}$ at $38.5 \mathrm{C}$ in $5 \% \mathrm{CO}_{2}$ in air with saturated humidity.

\section{Parthenogenetic activation (PA)}

At the end of the maturation culture, COCs were transferred into $3 \mathrm{ml}$ of the maturation medium supplemented with $0.1 \%(\mathrm{w} / \mathrm{v})$ hyaluronidase (Sigma) for $3 \mathrm{~min}$ and gently mixed. The oocytes were then denuded mechanically with a fine glass pipette in a small amount of hyaluronidase-free collection medium. The denuded oocytes were washed twice in maturation medium, and then treated with 50 mM Ca-ionophore (Sigma) dissolved in TCM199 with Hank's salt (Gibco) supplemented with $1 \mathrm{mg} / \mathrm{ml}$ PVA for $5 \mathrm{~min}$ in a dark room at room temperature. The oocytes were then washed twice and cultured in maturation medium supplemented with $2 \mathrm{mM}$ 6-dimethylaminopurine (6-DMAP, Sigma) for $5 \mathrm{~h}$. At the end of the 6-DMAP treatment, the oocytes were repeatedly washed and cultured in IVC medium.

\section{In vitro culture and time-lapse cinematography}

IVC was performed in $50 \mu \mathrm{l}$ drops of CR1aa medium [28] supplemeted with $5 \%$ calf serum covered with paraffin oil. At the end of insemination, putative zygotes were completely denuded from cumulus cells and spermatozoa by gentle pipetting with a fine glass pipette in preincubated IVC medium. Then, 15 to 25 embryos were placed separately in culture drops. Embryos were cultured at 38.5 $\mathrm{C}$ in $5 \% \mathrm{CO}_{2}$ under $20 \% \mathrm{O}_{2}$ tension in air with saturated humidity. The kinetics of embryo development were monitored by a real-time Cultured Cell Monitoring System (CCM-M1.4Z, Astec, Fukuoka, Japan). During the 175-h culture period, a total of 700 photographs of the embryos were taken with 15 min intervals using a plain objective with $4 \times$ magnification. Image stacks were analyzed using the CCM-M1.4 software (Astec).

\section{Evaluation of in vitro development and cleavage patterns}

The timing of developmental events was determined as time passed from insemination or Ca-ionophore treatment in IVF or PA embryos, respectively. After the first cell division, cleavage of the fastest cleaving blastomere was considered to be the beginning of the second cell cycle. After the second cell division, cleavage of the fastest cleaving blastomere was considered to be the beginning of the third cell cycle. The durations of the first, second and third cell cycles were recorded for each embryo including those that developed to the blastocyst stage (subsequently referred to as "viable" embryos) and also in embryos that failed to develop to the blastocyst stage ("non-viable" embryos). The cleavage pattern of each embryo was also evaluated at the first mitotic cell division. Based on the size and number of blastomeres and the presence/ absence of fragments and protrusions in the perivitelline space, the following morphological classes were distinguished: cell division to two blastomeres of the same size without signs of fragmentation was considered normal cleavage (NC; Fig. 1a); embryos with two blastomeres and several small fragments in the perivitelline space formed during first cleavage were classified as multiple fragments (MF; Fig. 1b); embryos with two blastomeres and a protrusion were classified as protrusion type embryos (PT; Fig. 1c); some embryos showed direct cleavage from the 1-cell stage to three or four blastomeres (3-4BL; Fig. 1d1, 2); and embryos with two blastomeres of different size were classified as unequal blastomeres (UB; Fig. 1e). All cleaved embryos were cultured for seven days. The resultant blastocysts were evaluated either by differential nuclear staining or by karyotyping.

\section{Blastocyst evaluation by differential staining of inner cell mass (ICM) and trophectoderm (TE) cells \\ Differential staining of ICM and TE nuclei in blastocysts was}




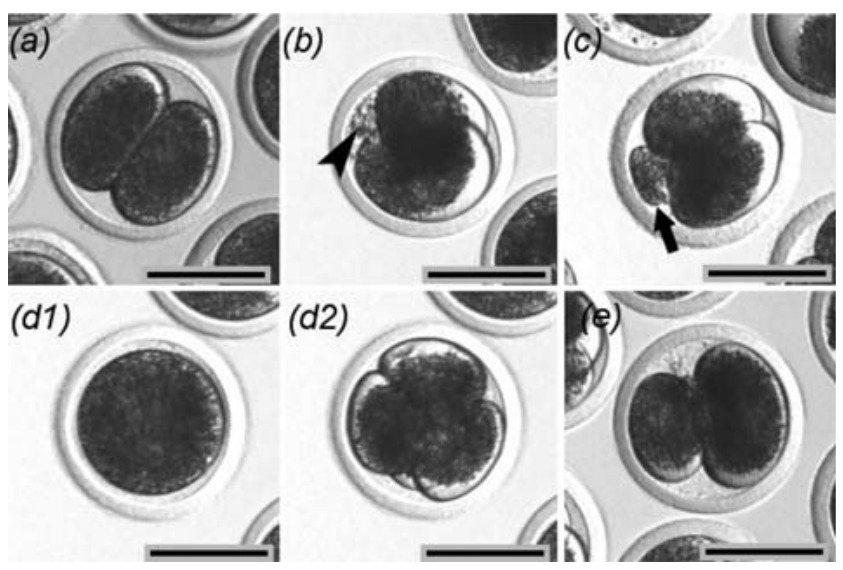

Fig. 1. Morphologic categories of embryos at the first cleavage. (a): Normal cleavage (NC) characterized by two blastomeres of the same size. (b): Multiple fragments (MF) characterized by two blastomeres and several small fragments (marked with an arrow head) in the perivitelline space. (c): An embryo with a protrusion (PT; marked with an arrow). (d): An embryo showing direct cleavage from the one-cell stage to four blastomeres (3-4BL) at $25 \mathrm{~h}$ and $30 \mathrm{~min}$ (d1) and at $25 \mathrm{~h}$ and $45 \mathrm{~min}$ after IVF (d2). (e): An embryo with two blastomeres of different size classified as unequal blastomeres (UB). The scale bars represent $100 \mu \mathrm{m}$.

performed by the method of Thouas et al. [29] with slight modifications. In brief, blastocysts and hatching/hatched blastocysts were simultaneously treated with a mixture of $0.1 \mathrm{mg} / \mathrm{ml}$ propidium iodide (PI, Sigma) and 0.2\% Triton X-100 (Sigma) dissolved in Dulbecco's phosphate buffered saline for 60 or $30 \mathrm{sec}$ (respectively) to permeabilize the membrane and stain the nuclei of TE cells. The embryos were then treated with $25 \mu \mathrm{g} / \mathrm{ml}$ Hoechst 33342 (Calbiochem, San Diego, CA, USA) dissolved in 99.5\% ethanol for $5 \mathrm{~min}$, then mounted on glass slides in glycerol droplets, flattened by cover slips and examined under UV light with an excitation wavelength of 330-385 nm using an epifluorescence microscope (IX-71, Olympus, Tokyo, Japan). The nuclei of TE cells- labeled by both PI and Hoechst-appeared pink or red, whereas the nuclei of ICM cells-labeled only by Hoechst-appeared blue. A digital image of each embryo was taken, and cell numbers of both cell types were counted using the NIH ImageJ (v. 1.40) software [30]. Total cell numbers were counted in all embryos. The numbers of ICM and TE cells were counted separately only in those embryos that had clearly distinguishable separate populations of red/pink and blue nuclei.

\section{Blastocyst karyotyping}

Chromosome samples of embryos were prepared by a method described previously by Yoshizawa et al. [31] with small modifications. Briefly, after IVC for 7 days, blastocysts were cultured for 14-17 h in CR1aa containing 5\% CS and $60 \mathrm{ng} / \mathrm{ml}$ vinblastine sulfate (Wako Pure Chemical Industries, Osaka, Japan). The blastocysts were then washed and incubated in $1 \%(\mathrm{w} / \mathrm{v})$ sodium citrate solution for $15 \mathrm{~min}$ and fixed by pouring $0.02 \mathrm{ml}$ acetic methanol (acetic acid:methanol=1:1) into $0.4 \mathrm{ml}$ of a hypotonic solution of sodium citrate. A blastocyst was placed on a glass slide in air with saturated humidity, immediately covered with a very small droplet of acetic acid to separate each cell, and then re-fixed with 3-4 drops of acetic alcohol (acetic acid:methanol=1:3). After being dried completely, chromosome samples were stained with 2\% (w/w) giemsa solution (Merck KGaA, Darmstadt, Germany) for $10 \mathrm{~min}$. Chromosome spreads were observed under a light microscope with a $\times 100$ plain objective. Digital images of each chromosome spread were taken, and chromosome numbers were analyzed using the NIH ImageJ (v. 1.40) software.

\section{Statistical analysis}

A total of sixteen and eleven replications of time-lapse recordings were performed with IVF and PA embryos, respectively. All data are expressed as means \pm SEM. Data of cell cycle length, embryo development and cell numbers were analyzed by one way ANOVA followed by Tukey's multiple comparison test using the KyPlot package (Ver. 4.0, Kyens Lab, Tokyo, Japan). Percentage data were arcsine transformed before analysis.

\section{Results}

\section{Length of initial cell cycles in viable and non-viable embryos}

In total, 285 of the 320 in vitro fertilized oocytes and 161 of the 241 activated oocytes cleaved in our system. The cleavage and blastocyst rates were similar between the IVF and PA oocytes (Table 1). As shown in Fig. 2, the onsets of the first and second mitotic divisions were significantly delayed in the non-viable embryos compared with the viable ones in both the IVF and PA groups (Fig. 2A). The onset of third cleavage was also significantly delayed in the non-viable embryos of the IVF group; however, there was no statistical difference in the onset of third cleavage between the viable and non-viable embryos of the PA group (Fig. 2A).

The length of one cell stage and duration of the second mitotic cell cycle were found to be significantly shorter in the viable embryos than in the non-viable embryos after both IVF (24.9 vs. $26.6 \mathrm{~h}$ and 8.7 vs. $10.0 \mathrm{~h}$, respectively) and PA (23.3 vs. $25.1 \mathrm{~h}$ and 10.4 vs. $14.6 \mathrm{~h}$, respectively). On the other hand, there was no statistical difference in the length of the third cell cycle between the viable and non-viable embryos produced by either IVF (8.5 and 9.6 $\mathrm{h}$, respectively) or parthenogenesis (17.8 and $16.7 \mathrm{~h}$, respectively; Fig. 2B).

\section{Frequency of embryos with different cleavage patterns at the first cleavage}

After IVF, 48.5\% of the cleaved embryos showed normal cleavage, $15.1 \%$ of them had multiple fragments and $10.3 \%$ of them had protrusions (Fig. 3). The frequency of embryos showing direct cleavage from one cell to 3-4 blastomeres was $14.1 \%$, and $18.6 \%$ of cleavages resulted in unequal blastomeres (Fig. 3). Twenty-two of the 285 cleaved embryos showed two types of abnormality. Parthenogenetic activation resulted in a similar distribution of frequencies in NC, MF and UB embryos as in IVF (59.2, 21.5 and $20.1 \%$, respectively); however, compared with the IVF group, the frequencies of PT and 3-4BL embryos were very low (2.0 and $1.8 \%$, respectively; Fig. 3). Because of their sparse occurrence, 
Table 1. Overall in vitro development of embryos generated by IVF or parthenogenesis

\begin{tabular}{lcccr}
\hline $\begin{array}{l}\text { Embryo } \\
\text { source }\end{array}$ & Total & Cleaved & Blastocyst & $\begin{array}{r}\text { Expanded } \\
\text { blastocyst }\end{array}$ \\
\hline IVF & 320 & $285(89.0 \pm 2.0)$ & $148(46.2 \pm 3.6)$ & $119(37.2 \pm 4.0)$ \\
PA & 241 & $161(81.5 \pm 3.1)$ & $102(42.7 \pm 4.6)$ & $59(24.7 \pm 3.7)$ \\
\hline
\end{tabular}

Data are presented as means \pm SEM. IVF=in vitro fertilization; $\mathrm{PA}=$ parthenogenetic activation.

In Vitro Fertilization

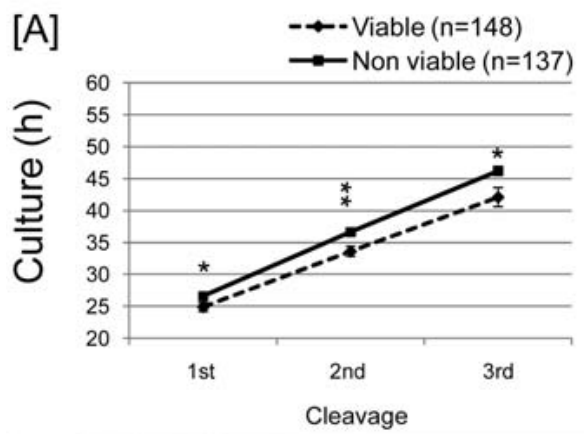

[B]

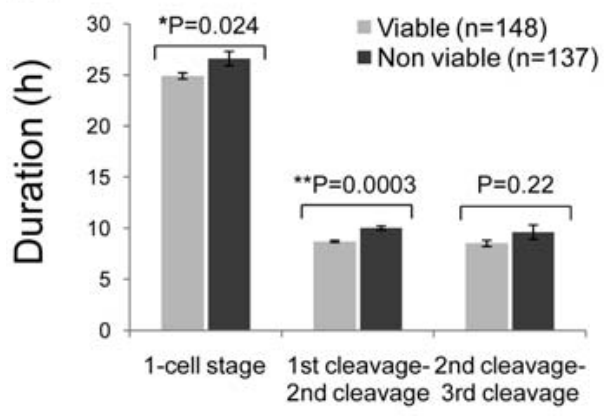

Parthenogenesis

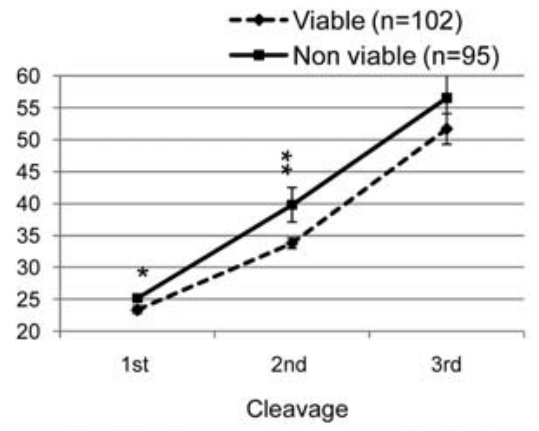

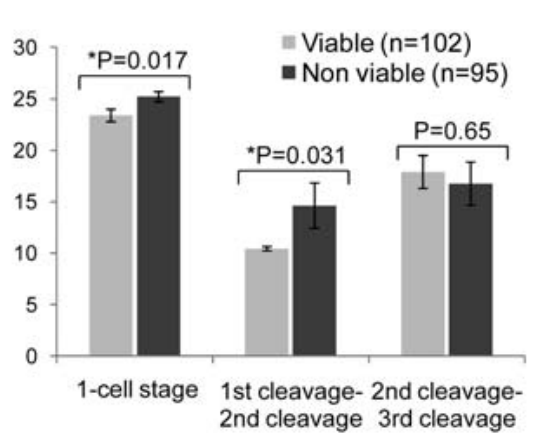

Fig. 2. The timing $[\mathrm{A}]$ and length $[\mathrm{B}]$ of initial cleavages and cell cycles in cleaved viable and non-viable cleaved embryos generated either by IVF or parthenogenesis. Embryos with the ability to develop to the blastocyst stage in vitro were considered as "viable". A total of sixteen and eleven replications of time-lapse recordings were performed with IVF and PA embryos, respectively. Data are presented as means \pm SEM. Asterisks denote significant differences $(* \mathrm{P}<0.05$ and $* * \mathrm{P}<0.01)$.

further examinations of the in vitro development and blastocyst quality of PT and 3-4BL embryos were not applicable. The frequency of NC-type cleavage was significantly higher, whereas the frequencies of PT and UB type divisions were lower in the viable embryos compared with the non-viable ones in the IVF group (Fig. 4). In the PA group, the frequency of MF cleavage was higher in the non-viable embryos than in viable embryos, whereas the frequencies of the NC, PT, 3-4BL and UB cleavage types did not differ significantly between the viable and non-viable embryos (Fig. 4).

\section{Length of initial cell cycles in embryos with different cleavage patterns}

As shown in Fig. 5, the duration of the one-cell stage in IVF embryos showing normal cleavage was found to be significantly shorter than in the MF, PT, 3-4BL and UB groups (24.7 vs. 26.6, 26.3, 26.0 and $27.7 \mathrm{~h}$, respectively). Nevertheless, there was no difference in the length of the second (ranging from 8.8 to $9.7 \mathrm{~h}$ ) and third cell cycles (ranging from 8.2 to $9.4 \mathrm{~h}$ ) between the morphological categories (Fig. 5). In the case of parthenogenetic embryos, no significant difference was detected in the length of the one-cell stage and second and third cell cycles (Fig. 5).

\section{In vitro development of embryos with different cleavage patterns}

In vitro culture of IVF oocytes revealed that the frequency of developmental arrest before the third mitotic cell cycle was significantly lower in the NC embryos than in the embryos of the UB 
In Vitro Fertilization

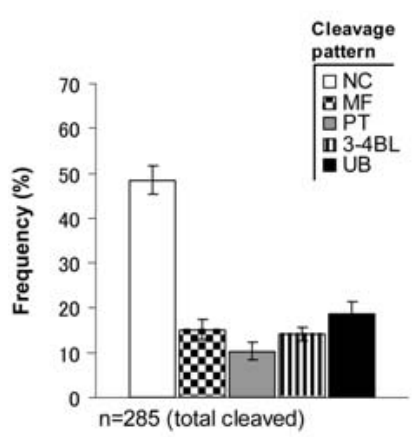

Parthenogenesis

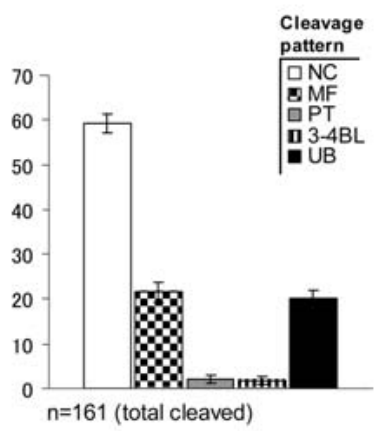

Fig. 3. Frequency of embryos with different cleavage patterns at first cleavage in IVF and PA embryos. NC=normal cleavage; $\mathrm{MF}=$ multiple fragments; $\mathrm{PT}=$ protrusion formation; $3-4 \mathrm{BL}=$ direct cleavage from one cell to 3 or 4 blastomeres; $\mathrm{UB}=$ unequal blastomeres. Data are presented as means \pm SEM.
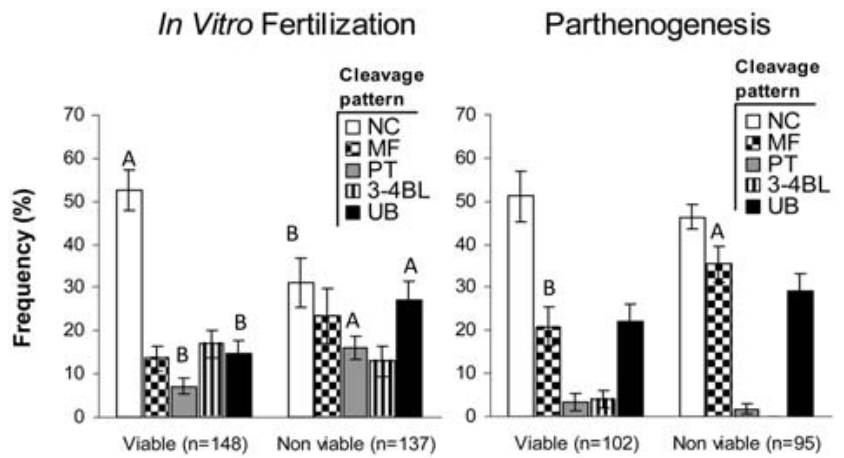

Fig. 4. Frequency of embryos with different cleavage patterns at first cleavage in viable and non-viable embryos. $\mathrm{NC}=$ normal cleavage; $\mathrm{MF}=$ multiple fragments; $\mathrm{PT}=$ protrusion formation; 3$4 \mathrm{BL}=$ direct cleavage from one cell to 3 or 4 blastomeres; $\mathrm{UB}=$ unequal blastomeres. Data are presented as means \pm SEM. A and $\mathrm{B}$ denote significant differences $(\mathrm{P}<0.05)$.

group (7.6 and $33.8 \%$, respectively), whereas intermediate values were detected in the MF, PT and 3-4BL groups (17.6, 17.1 and $14.5 \%$, respectively; Fig. 6$)$. The percentage of NC embryos that developed to the blastocyst stage was significantly higher than those of the embryos in the MF, PT and UB groups but similar to that of the embryos in the 3-4BL group (66.9, 40.5, 26.5, 35.6 and $56.7 \%$, respectively; Fig. 6). Likewise, the developmental rate to the expanded blastocyst stage of the NC embryos was significantly higher than those of the MF and PT embryos (50.8, 27.5 and $26.5 \%$, respectively) but did not differ from those of the embryos in the 3-4BL and UB groups (34.8 and 33.3\%, respectively; Fig. 6). In the parthenogenetic embryos, no significant difference was detected in the frequency of early developmental block between the morphologic classes (Fig. 6). On the other hand, similar to IVF embryos, higher rates of blastocysts and expanded blastocysts were observed in the embryos of the NC group than in the MF embryos

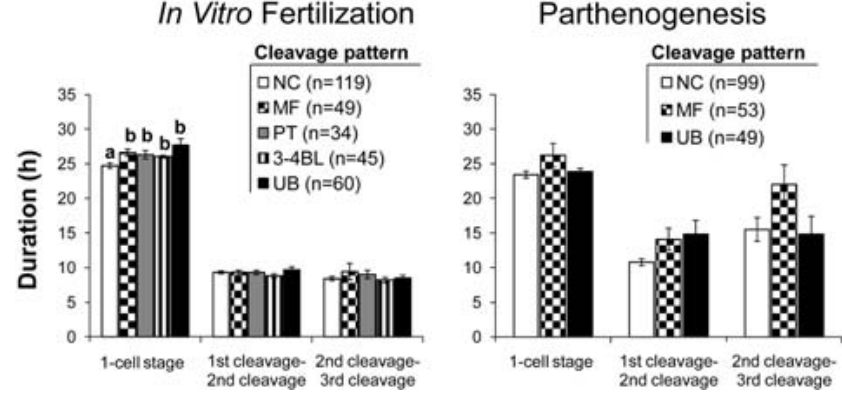

Fig. 5. The lengths (h) of initial cell cycles in cleaved IVF and PA embryos showing different cleavage patterns at first cell division. $\mathrm{NC}=$ normal cleavage; $\mathrm{MF}=$ multiple fragments; $\mathrm{PT}=$ protrusion formation; 3-4BL=direct cleavage from one cell to 3 or 4 blastomeres; UB=unequal blastomeres. Data are presented as means \pm SEM. Significant differences are denoted by $a$ and $b$ $(\mathrm{P}<0.05)$.
In Vitro Fertilization

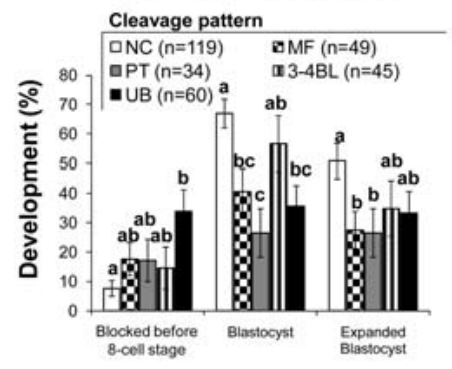

Parthenogenesis

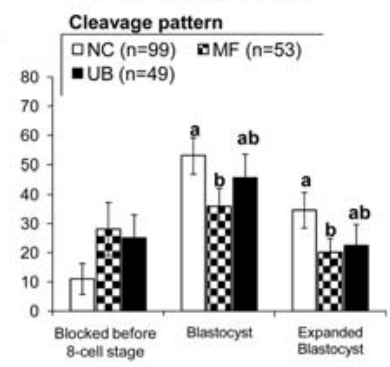

Fig. 6. In vitro development of IVF and PA embryos showing different cleavage patterns at first cell division. NC= normal cleavage; $\mathrm{MF}=$ multiple fragments; $\mathrm{PT}=$ protrusion formation; $3-4 \mathrm{BL}=$ direct cleavage from one cell to 3 or 4 blastomeres; UB=unequal blastomeres. Data are presented as means \pm SEM. Significant differences are denoted by a, $\mathrm{b}$ and $\mathrm{c}(\mathrm{P}<0.05)$.

(53.0 vs. $35.9 \%$ and 34.5 vs. $20.1 \%$, respectively), whereas the blastocyst and expanded blastocyst rates of the embryos in the UB group reached intermediate levels (45.7 and 22.5\%, respectively).

\section{Total numbers of nuclei, ICM and TE cells in blastocysts}

In the IVF embryos, the mean number of total nuclei in the NC blastocysts did not differ from those of the blastocysts in the MF, 34BL and UB groups but was higher than that of the PT embryos (152.9, 155.6, 121.6, 149.3 and 115.1, respectively) (Fig. 7). There was no significant difference between different groups of IVF blastocysts in the numbers of ICM and TE cells and the rates of ICM cells.

Blastocysts that developed from NC parthenotes contained a significantly higher number of blastomeres than those of the MF group, whereas the total cell number in the parthenogenetic UB blastocysts did not differ significantly from these groups (98.2, 70.3 and 80.1, respectively; Fig. 7). Similarly, the number of TE cells in NC parthenotes was significantly higher than that of in MF 
In Vitro Fertilization

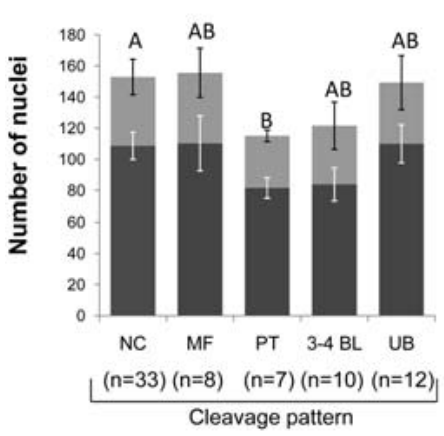

Parthenogenesis

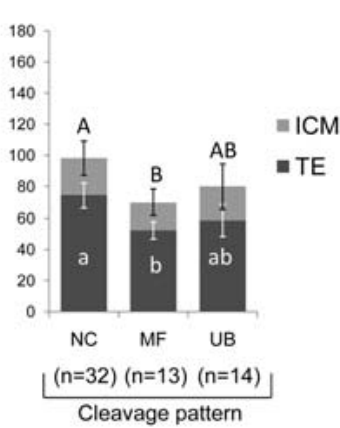

Fig. 7. Numbers of nuclei in IVF- and PA-derived blastocysts on day 7 IVC developing from embryos showing different cleavage patterns at first cell division. $\mathrm{NC}=$ normal cleavage; $\mathrm{MF}=$ multiple fragments; $\mathrm{PT}=$ protrusion formation; $3-4 \mathrm{BL}=$ direct cleavage from one cell to 3 or 4 blastomeres; $U B=$ unequal blastomeres. A and $\mathrm{B}$ and $\mathrm{a}$ and $\mathrm{b}$ denote significant differences in total and TE cell numbers, respectively $(\mathrm{P}<0.05)$. parthenotes whereas the UB group showed an intermediate value (74.5, 52.3 and 58.7, respectively). There was no significant difference between the three types of parthenotes in the numbers and rate of ICM cells (Fig. 7).

\section{Chromosome numbers in blastocysts}

As shown in Fig. 8, NC, MF, PT and UB embryos were characterized by relatively high rates of diploid blastocysts (ranging between 66.6 and $80 \%$ in IVF embryos and between 50 and $75 \%$ in parthenotes) and moderate incidences of mixoploidy (most commonly diploid/tetraploid composition) and polyploidy. On the other hand, only $25 \%$ of the embryos were diploid in the 3-4BL group, and most (6 out of 8 ) blastocysts showed abnormal ploidy such as haploidy, polyploidy, mixoploidy or chaotic chromosome numbers in blastomeres (Fig. 8). It must be noted that statistical analysis was not carried out due to the scarce occurrence of MF, PT, 3-4BL and UB blastocysts.

\section{Discussion}

\section{Relationship between the length of initial cell cycles and embryo viability}

Our results confirmed that after IVF or parthenogenesis, the length of the one cell stage and the second mitotic cell cycle reflect the ability of embryos to develop to the blastocyst stage. Similar results in bovine embryos have been reported previously [14]. Our results, in accordance with previous observations [18], for parthenogenetic embryos clearly demonstrated that the correlation between early cleavage and high developmental competence exists in embryos that were generated without the contribution of spermatozoa. This confirms that mainly maternal factors are involved in this phenomenon and that the ability of the oocyte to respond to stimulus driven by the penetrating sperm or to support sperm head decondensation, and male pronucleus formation may not play a role in the timing of the first embryonic cleavage. Genetic regula-

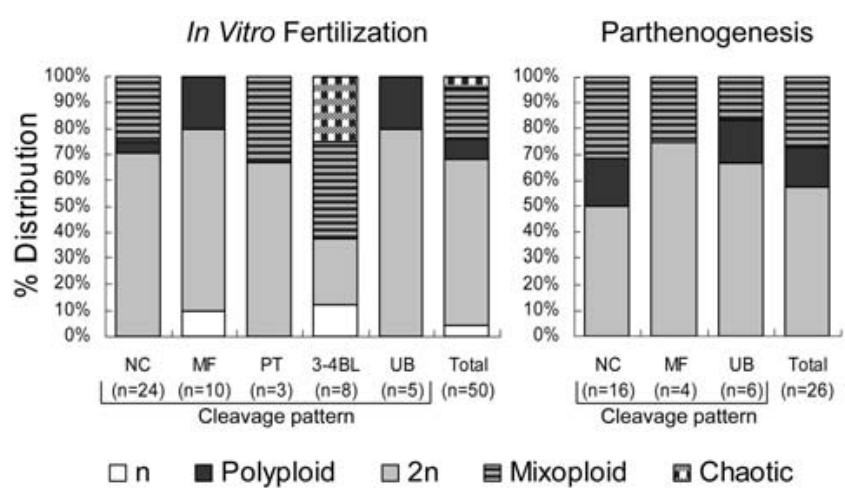

Fig. 8. Ploidy of IVF- and PA-derived blastocysts developing from embryos showing different cleavage patterns at first cell division. $\mathrm{NC}=$ normal cleavage $\mathrm{MF}=$ multiple fragments; $\mathrm{PT}=$ protrusion formation; $3-4 \mathrm{BL}=$ direct cleavage from one cell to 3 or 4 blastomeres; UB=unequal blastomeres. Statistical analysis was not carried out due to the scarce occurrence of MF, PT, 34BL and UB blastocysts.

tion of early cleavage has been proven by identification of the Ped (preimplantation embryo development) gene, which regulates timing of first cleavage and preimplantation embryonic growth in murine and bovine embryos [32, 33]. In fact, a number of genes appear to be involved in the regulation of the timing of early embryonic cleavages [34-37], and their expression is conducted mainly by maternally-derived mRNAs that accumulate in the oocyte during its growth phase, since initiation of genomic activation starts from the 8-16 cell stage in bovine embryos [38]. In this respect, the actual level of maternal mRNAs in oocytes plays a pivotal role both in the timing of early cleavages and in the developmental competence of early embryos [39]. In accordance with previous results $[14,40]$, the timing of the second embryonic cleavage and length of the second cell cycle also seem to be reliable predictors of further development and should be considered as a selection marker for in vivo produced embryos. On the other hand-despite the differences in the length of first and second cell cycles - the third mitotic cycles were similar in the viable and nonviable embryos of both the IVF and parthenogenetic groups. This result is not in agreement with the report of Holm et al. [40], and the reason of this discrepancy is not clearly understood. In our study, the most apparent difference between the early developmental kinetics of IVF and PA embryos was observed in the length of the third cell cycle. Although only slight differences were detected in the durations of their one-cell stages and second cell cycles, the length of the third cell cycle in the parthenogenetic embryos appeared to be longer than that in the IVF embryos, irrespective of their viability. This result is in accordance with a previous report of Holm et al. [18], who suggested the following two possible reasons for this phenomenon: 1 ) the extensive incidence of mixoploidy and polyploidy in PA embryos and 2) an early (shifted) initiation of transition from maternal to embryo control. In our study, however, we did not find convincing differences in the frequencies of embryos with abnormal chromosome numbers between the IVF and PA groups (Fig. 8), suggesting the involvement of a shift in 
genomic transition in the prolonged third cell cycle in PA embryos.

Relationship between the cleavage pattern and embryo viability

Our results demonstrate that the cleavage pattern at the first cell division reflects not only the in vitro developmental ability of the embryos but also the quality of the resultant blastocysts. The appearance of small fragments or protrusions in the perivitelline space and blastomeres of unequal size were associated with reduced blastocyst rates. Embryos with unequal blastomeres tended to be arrested before passing through the third cell division. Regarding the cell numbers in blastocysts, a difference was observed between IVF and parthenogenetic embryos having multiple fragments; parthenogenetic MF embryos had a significantly reduced total and TE cell number compared with NC embryos, whereas in the IVF group, the total and TE cell numbers were similar in blastocysts obtained from these morphological categories.

Although the cell numbers in PT blastocysts were lower than in normal embryos, it can be stated that the blastocysts that developed from this morphological class were normal in terms of ICM/TE rates and chromosome numbers. More attention should be paid, however, to those embryos that cleave directly to 3 or 4 blastomeres from the one-cell stage. This type of cell division-along with protrusion formation-has been reported to occur in polyspermic human oocytes [24]. Direct cleavage from one cell to more than two blastomeres is believed to be related to formation of tripolar spindles caused by abnormally high numbers of centrioles driven by excessively penetrating spermatozoa in polyspermic oocytes [41]. In human embryos, tri- or tetrapolar spindle formation is often associated with abnormal distribution of chromosomes during cleavage in resultant blastomeres [24, 25]. Unlike embryos with protrusions, which had normal diploid chromosome numbers in all cases, a high incidence of aneuploidy was found in those polyspermic human embryos that cleaved from 1 cell to three blastomeres [24]. Our results reveal not only the surprisingly high incidence of the 3-4BL cleavage pattern in a bovine IVP system, but also the following two remarkable characteristics of these embryos: 1) their normal developmental competence to the blastocyst/expanded blastocyst stage and 2) the high frequency of abnormal chromosome numbers. Embryo selection based on developmental speed at early stages without observation of the cleavage pattern at the first cell division may lead to inappropriate selection of such embryos and result in low pregnancy rates or abortions. In the present study-unlike the case of IVF-direct division to 3 or 4 blastomeres and protrusion formations were rarely observed after parthenogenesis, indicating the relation of these types of cell division to sperm penetration. Such cleavage patterns during the first cell division are actually believed to be involved in the occasional correction of abnormal ploidy in polyspermic embryos [24, 42, 43]. In our system, the frequency of polyspermy is around 10-20\% (unpublished data), which corresponds with the occurrence of PT and 3-4BL embryos. Since all PT blastocysts and some of the 3-4BL embryos were found to be diploids or diploid/tetraploid mosaics and the transfer of 3-4BL derived blastocysts resulted in some pregnancies, the possibility of their involvement in ploidy correction cannot be excluded. According to our preliminary results, seven transfers of 3-4BL embryos resulted in two pregnancies (28.5\%) whereas the pregnancy rates of the NC and MF embryos were both 50\% (6/12 and 1/ 2 , respectively). Pregnancies were not obtained by transfer of PT and UB embryos (0/3 and $0 / 1$, respectively). It must be noted, however, that adequate results for pregnancy and birth rates after transfer are not yet available for the statistical demonstration of the developmental competence embryos in the different classes. Interestingly, 3-4BL cell division has also been observed after intracytoplasmic injection of single sperm heads in pigs (personal communication), raising further questions regarding the formation of this particular cleavage type.

\section{Relationship between lengths of initial cell cycles and cleavage patterns}

Previous studies have revealed possible links between the timing of first cleavage and the appearance fragments or uneven blastomeres size in human, bovine and porcine embryos $[13,16]$. In our study - as shown in Fig. 5-embryos showing a normal cleavage pattern were characterized not only by high developmental competence but also by a significantly shorter one-cell stage than embryos belonging to the other morphology classes. Nevertheless, no difference was recorded between the normal and abnormal cleavage types in the length of the second cell cycle. Our results suggest that the extended length of the one-cell stage in non-viable embryos may be related with abnormal cleavage patterns; however, the extended length of the second cell cycle has no relation with the pattern of cell division. It is possible that the presence of fragments or unequally sized blastomeres at the first cleavage is an additional indicator of cellular deficiencies that some unviable oocytes are stricken with. Supporting this theory, embryo fragmentation has been found to correlate with apoptosis [44] and altered gene expressions [45], whereas unequal blastomeres size appears to be associated with aneuploidy and multinucleation of embryos [23].

In conclusion, our results reveal that both the lengths of the first and second embryonic cell cycles and the cleavage pattern during first cell division are potent predictors of developmental competence and should be viewed simultaneously for selection of good quality embryos for embryo transfer.

\section{Acknowledgments}

The authors thank M Oguro and S Oishi for technical assistance and N Hitomi for transportation of ovaries. This work was supported by the Research and Development Program for New Bioindustry Initiatives.

\section{References}

1. Galli C, Duchi R, Crotti G, Turini P, Ponderato N, Colleoni S, Lagutina I, Lazzari G. Bovine embryo technologies. Theriogenology 2003; 59: 599-616.

2. Bavister BD. Culture of preimplantation embryos: facts and artifacts. Hum Reprod Update 1995; 1: 91-148.

3. Lonergan P, Fair T, Corcoran D, Evans AC. Effect of culture environment on gene expression and developmental characteristics in IVF-derived embryos. Theriogenology 2006; 65: 137-152.

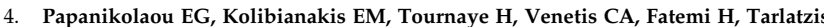
B, Devroey P. Live birth rates after transfer of equal number of blastocysts or cleavage-stage embryos in IVF. A systematic review and meta-analysis. Hum Reprod 2008; 
23: 91-99.

5. Ebner T, Moser M, Sommergruber M, Tews G. Selection based on morphological assessment of oocytes and embryos at different stages of preimplantation development: a review. Hum Reprod Update 2003; 9: 251-262.

6. Salumets A, Hydén-Granskog C, Suikkari AM, Tiitinen A, Tuuri T. The predictive value of pronuclear morphology of zygotes in the assessment of human embryo quality. Hum Reprod 2001; 16: 2177-2181.

7. James AN, Hennessy S, Reggio B, Wiemer K, Larsen F, Cohen J. The limited importance of pronuclear scoring of human zygotes. Hum Reprod 2006; 21: 1599-1604.

8. McLaren A, Bowman P. Genetic effects on the timing of early development in the mouse. J Embryol Exp Morph 1973; 30: 491-498.

9. Shoukir Y, Campana A, Farley T, Sakkas D. Early cleavage of in-vitro fertilized human embryos to the 2-cell stage: a novel indicator of embryo quality and viability. Hum Reprod 1997; 12: 1531-1536.

10. Lundin K, Bergh C, Hardarson T. Early embryo cleavage is a strong indicator of embryo quality in human IVF. Hum Reprod 2001; 16: 2652-2657.

11. Fenwick J, Platteau P, Murdoch AP, Herbert M. Time from insemination to first cleavage predicts developmental competence of human preimplantation embryos in vitro. Hum Reprod 2002; 17: 407-412.

12. Grisart B, Massip A, Dessy F. Cinematographic analysis of bovine embryo development in serum-free oviduct-conditioned medium. J Reprod Fertil 1994; 101: 257.

13. Van Soom A, Ysebaert MT, de Kruif A. Relationship between timing of development, morula morphology, and cell allocation to inner cell mass and trophectoderm in in vitro-produced bovine embryos. Mol Reprod Dev 1997; 47: 47-56

14. Holm P, Shukri NN, Vajta G, Booth P, Bendixen C, Callesen H. Developmental kinetics of the first cell cycles of bovine in vitro produced embryos in relation to their in vitro viability and sex. Theriogenology 1998; 50: 1285-1299.

15. Lonergan P, Khatir H, Piumi F, Rieger D, Humblot P, Boland MP. Effect of time interval from insemination to first cleavage on the developmental characteristics, sex and pregnancy rates of following transfer of bovine preimplantation embryos. $J$ Reprod Fertil 1999; 117: 159-167.

16. Booth PJ, Watson TJ, Leese HJ. Prediction of porcine blastocyst formation using morphological, kinetic, and amino acid depletion and appearance criteria determined during the early cleavage of in vitro-produced embryos. Biol Reprod 2007; 77: 765-779.

17. Lechniak D, Pers-Kamczyc E, Pawlak P. Timing of the first zygotic cleavage as a marker of developmental potential of mammalian embryos. Reprod Biol 2008; 8: $23-42$.

18. Holm P, Booth PJ, Callesen H. Developmental kinetics of bovine nuclear transfer and parthenogenetic embryos. Cloning Stem Cells 2003; 5: 133-142.

19. Ziebe S, Petersen K, Lindenberg S, Andersen AG, Gabrielsen A, Andersen AN Embryo morphology or cleavage stage: how to select the best embryos for transfer after in-vitro fertilization. Hum Reprod 1997; 12: 1545-1549.

20. Alikani M, Cohen J, Tomkin G, Garrisi GJ, Mack C, Scott RT. Human embryo fragmentation in vitro and its implications for pregnancy and implantation. Fertil Steril 1999; 71: 836-842.

21. Ebner T, Yaman C, Moser M, Sommergruber M, Pölz W, Tews G. Embryo fragmentation in vitro and its impact on treatment and pregnancy outcome. Fertil Steril 2001; 76: 281-285.

22. Ciray HN, Karagenç L, Ulug U, Bener F, Bahçeci M. Early cleavage morphology affects the quality and implantation potential of day 3 embryos. Fertil Steril 2006; 85: 358-365.

23. Hardarson T, Hanson C, Sjögren A, Lundin K. Human embryos with unevenly sized blastomeres have lower pregnancy and implantation rates: indications for aneuploidy and multinucleation. Hum Reprod 2001; 16: 313-318.

24. Kola I, Trounson A, Dawson G, Rogers P. Tripronuclear human oocytes: altered cleavage patterns and subsequent karyotypic analysis of embryos. Biol Reprod 1987; 37: 395-401.

25. Chatzimeletiou K, Morrison EE, Prapas N, Prapas Y, Handyside AH. Spindle abnormalities in normally developing and arrested human preimplantation embryos in vitro identified by confocal laser scanning microscopy. Hum Reprod 2005; 20: 672-682
26. Imai K, Tagawa M, Yoshioka H, Matoba S, Narita M, Inaba Y, Aikawa Y, Ohtake M, Kobayashi S. The efficiency of embryo production by ovum pick-up and in vitro fertilization in cattle. J Reprod Dev 2006; 52 (Suppl): 19-29.

27. Brackett BG, Oliphant G. Capacitation of rabbit spermatozoa in vitro. Biol Reprod $1975 ; 12: 260-274$

28. Rosenkrans Jr CF, Zeng GQ, Mcnamara GT, Schoff PK, First NL. Development of bovine embryos in vitro as affected by energy substrates. Biol Reprod 1993; 49: 459-462.

29. Thouas GA, Korfiatis NA, French AJ, Jones GM, Trounson AO. Simplified technique for differential staining of inner cell mass and trophectoderm cells of mouse and bovine blastocysts. Reprod Biomed Online 2001; 3: 25-29.

30. Abramoff MD, Magelhaes PJ, Ram SJ. Image processing with ImageJ. Biophoton In 2004; $11: 36-42$

31. Yoshizawa M, Matsukawa A, Matsumoto K, Suzuki K, Yasumatsu K, Zhu S, Muramatsu S. Required concentration and time of vinblastine treatment for chromosome preparation in bovine blastocysts derived from in vitro fertilization. J Reprod Dev 1998, 44: 59-64.

32. Goldbard SB, Verbanac KM, Warner CM. Genetic analysis of H-2 linked gene(s) affecting early mouse embryo development. J Immunogenet 1982; 9: 77-82.

33. Fair T, Gutierrez-Adan A, Murphy M, Rizos D, Martin F, Boland MP, Lonergan P Search for the bovine homolog of the murine ped gene and characterization of its messenger RNA expression during bovine preimplantation development. Biol Reprod 2004; 70: 488-494.

34. Lonergan P, Gutiérrez-Adán A, Pintado B, Fair T, Ward F, Fuente JD, Boland M Relationship between time of first cleavage and the expression of IGF-I growth factor its receptor, and two housekeeping genes in bovine two-cell embryos and blastocysts produced in vitro. Mol Reprod Dev 2000; 57: 146-152.

35. Fair T, Murphy M, Rizos D, Moss C, Martin F, Boland MP, Lonergan P. Analysis of differential maternal mRNA expression in developmentally competent and incompetent bovine two-cell embryos. Mol Reprod Dev 2004; 67: 136-144.

36. Patel OV, Bettegowda A, Ireland JJ, Coussens PM, Lonergan P, Smith GW. Func tional genomics studies of oocyte competence: evidence that reduced transcript abundance for follistatin is associated with poor developmental competence of bovine oocytes. Reproduction 2007; 133: 95-106.

37. Wrenzycki C, Herrmann D, Niemann H. Messenger RNA in oocytes and embryos in relation to embryo viability. Theriogenology 2007; 68 (Suppl 1): 77-83.

38. Telford NA, Watson AJ, Schultz GA. Transition from maternal to embryonic control in early mammalian development: a comparison of several species. Mol Reprod Dev 1990; 26: 90-100.

39. Fair T, Murphy M, Rizos D, Moss C, Martin F, Boland MP, Lonergan P. Analysis of differential maternal mRNA expression in developmentally competent and incompetent bovine two-cell embryos. Mol Reprod Dev 2004; 67: 136-144.

40. Holm P, Booth PJ, Callesen H. Kinetics of early in vitro development of bovine in vivoand in vitro-derived zygotes produced and/or cultured in chemically defined or serum-containing media. Reproduction 2002; 123: 553-565.

41. Sathananthan AH, Kola I, Osborne J, Trounson A, Ng SC, Bongso A, Ratnam SS Centrioles in the beginning of human development. Proc Natl Acad Sci 1991; 88: 48064810.

42. Han YM, Wang WH, Abeydeera LR, Petersen AL, Kim JH, Murphy C, Day BN, Prather RS. Pronuclear location before the first cell division determines ploidy of polyspermic pig embryos. Biol Reprod 1999; 61: 1340-1346.

43. Funahashi H. Polyspermic penetration in porcine IVM-IVF systems. Reprod Fertil Der 2003; $15: 167-177$

44. Mateusen B, Van Soom A, Maes DG, Donnay I, Duchateau L, Lequarre AS. Porcine embryo development and fragmentation and their relation to apoptotic markers: a cinematographic and confocal laser scanning microscopic study. Reproduction 2005, 129: $443-452$.

45. Wells D, Bermúdez MG, Steuerwald N, Malter HE, Thornhill AR, Cohen J. Association of abnormal morphology and altered gene expression in human preimplantation embryos. Fertil Steril 2005; 84: 343-355. 